\title{
Assessment methodology for Lean Practices in healthcare organizations: case study in a Brazilian public hospital
}

\author{
Guilherme Tortorella $^{a *}$ (D), Byanca Pinheiro Augusto ${ }^{a}$, Sérgio Luiz Braga França ${ }^{\mathrm{b}}$ (D), \\ Rapinder Sawhneyc \\ aUniversidade Federal de Santa Catarina, Florianópolis, SC, Brasil \\ bUniversidade Federal Fluminense, Niterói, RJ, Brasil \\ 'University of Tennessee, Knoxville, TN, United States of America \\ *g.tortorella@ufsc.br
}

\begin{abstract}
Paper aims: This article aims at proposing a methodology for assessing lean practices in healthcare organizations that are undergoing a lean implementation.

Originality: The proposed methodology evaluates healthcare organizations and help managers identify the relationships intensities between their problems and lean practices. This application occurs in a case study in an Emergency Department from a Brazilian public hospital.
\end{abstract}

Research method: The proposed methodology provides a theoretical framework that addresses lean practices according to fundamental aspects of the organization, such as people, partnerships, results, processes and leadership, corroborating to a systemic view of lean implementation and facilitating its long-term sustainability.

Main findings: Our findings provide guidelines for the public hospital leadership, allowing a clear focus on the improvement efforts that can mitigate problems.

Implications for theory and practice: Due to contextual diversity, the understanding of the critical success factors for lean implementation under such conditions deserves attention. Hence, the proposed method allows practitioners and academics to better comprehend the lean implementation within healthcare organizations. Such enhanced comprehension allows to anticipate potential issues throughout the lean implementation, entailing more assertive efforts. Moreover, accounting for specific problems when designing the lean implementation avoids the utilization of a general and ineffective approach.

Keywords

Lean healthcare. Assessment. Public hospital.

How to cite this article: Tortorella, G., Augusto, B. P., França, S. L. B., \& Sawhney, R. (2019). Assessment methodology for Lean Practices in healthcare organizations: case study in a Brazilian public hospital. Production, 29, e20180080. https:// doi.org/10.1590/0103-6513.20180080.

Received: Sept. 1, 2018; Accepted: Mar. 19, 2019.

\section{Introduction}

Many attempts to apply quality management practices have been carried out in healthcare services (Ruiz \& Simon, 2004), which generally lack an efficient management system. Long waiting times, unnecessary increase in the number of examinations, high operating costs, staff shortages, and medical errors are some of the recurring problems in health services (Silberstein, 2006). In this sense, it is necessary for managers and leaders of healthcare organizations to understand their processes, improving them in order to provide a treatment that is safer, more efficient and better qualifyed. In recent years, discussions have centered on the potential of applying principles 
and practices derived from Lean Manufacturing (LM) systems in healthcare services, given the increased efficiency they can provide (Kollberg et al., 2006; Kim et al., 2006; Dickson et al., 2009). The principles and practices derived from LM appear as a way to support these objectives, through the identification and elimination of waste (Graban, 2012). Thus, the term Lean Healthcare (LH) emerged as a reference for the integration of such principles and practices into healthcare management (Souza, 2009).

There is general acknowledgement on the potential of such approach in healthcare services and its benefits. However, this potential has not yet been explored in its entirety and requires implementation efforts in situations of greater complexity (Proudlove et al., 2008; Saurin et al., 2013; Mannon, 2014; Righi \& Saurin, 2015). Similarly, despite the gains in efficiency and quality that lean practices have brought to manufacturing environments, the applicability and adaptation of these practices to healthcare still face challenges (Young \& McClean, 2009), such as healthcare leadership development and process variability (Tortorella et al., 2017a). In addition, $\mathrm{LH}$ is often misinterpreted since healthcare organizations usually begin to implement practices without prior understanding of the structural and cultural conditions required for implementation (Dahlgaard \& Mi Dahlgaard-Park, 2006). Mazzocato et al. (2010) argue that there is still little evidence of a consolidated methodology for lean implementation in healthcare. The focus of $\mathrm{LH}$ implementation has been directed mainly to practices and tools (Radnor et al., 2012). However, many authors argue that the success of lean implementation lies in the understanding that $\mathrm{LH}$ comprises a management system, not simply a set of practices (Mann, 2005; Kim et al., 2006; Ballé \& Régnier, 2007). Anvari et al. (2014a, b) state that the selection of lean practices is one of the major challenges faced by manufacturing managers as it can determine the success or failure of lean implementation in the organization.

Due to the diversity of contexts found in healthcare services, the understanding of the critical success factors (CSF) for lean implementation under such conditions deserves further attention (Jones, 2006; Al-Balushi et al., 2014). The identification of CSF is important to assist management succeed in LM implementation. Hence, if these CSF are not properly established within the organization, the implementation is more likely to fail (Yew Wong, 2005). The literature suggests that change management for a LM should take into account factors such as: the impact of changes over employees, the effect of a positive leadership profile and the effectiveness of existing communication channels (Bessant \& Francis, 1999). Achanga et al. (2006) emphasized the need to analyze the factors considered critical to the success of lean implementation in an organization. However, although the CSF and lean practices (LP) are widely studied and acknowledged as fundamental to lean implementation (Jeyaraman \& Kee Teo, 2010; Mazzocato et al., 2010; Costa \& Godinho Filho, 2016), literature evidence with respect to the relationship between both is still scarce (D'Andreamatteo et al., 2015). Methods from Dahlgaard et al. (2011) and Bastian et al. (2016), for example, exclusively approach the assessment and diagnosis of problems within the organization; while the method of McConnell et al. (2014) exclusively evaluates management practices in a general way (including LP). Moreover, such a gap can be amplified when considering the context of healthcare organizations.

Thus, this article aims at proposing a methodology for assessing LP in healthcare organizations that are undergoing a lean implementation. The proposed methodology combines concepts of maturity analysis in lean implementation (Tortorella \& Fogliatto, 2014) with the model developed by Dahlgaard et al. (2011), which aims to evaluate healthcare organizations and help managers identify the relationships intensities between their problems and practices.

The proposed methodology groups LH implementation problems according to five CSF, thereby, based on the understanding of the relationship intensity between LP and the CSF weighted by both the occurrence frequency of problems and adoption level of LP, it is possible to list the most critical LP for the LH implementation in the organization. This identification allows the establishment of a practical orientation in which the organizational context is taken into account to determine an appropriate prioritization for the $\mathrm{LH}$ implementation. Finally, the inclusion of a multicriteria analysis allows the consideration of other organizational attributes to support the direction of improvement efforts of the hospital management.

\section{Background}

\subsection{Lean healthcare practices}

In healthcare, as in the manufacturing industry, LP need to be adapted to the specificities of each service (Drotz \& Poksinska, 2014). For Cookson et al. (2011), the application of LP in healthcare is becoming increasingly common for the maintenance of an efficient service of high quality from the perspective of patients and employees. Moreover, if analyzed under the context of emerging countries, the opportunities for research are even greater (Souza, 2009). Daultani et al. (2015) affirmed that methods that address the selection process of the most appropriate LP for healthcare organizations are still lacking, which entails that this selection occurs 
through speculation and intuition. Fillingham (2007) reported that, through the use of 5S, kaizen events, value stream mapping, standardized work, pull systems and continuous flow, Bolton Hospitals in UK achieved significant improvements. Kim et al. (2006) described the case of the University of Michigan hospital where processes were redesigned, reducing and standardizing the setup activities.

In this sense, the selection of appropriate practices for the improvement of processes and identification of their applicability in the operational context represent an additional problem for managers and professionals (Shah \& Ward, 2007). There is a large number of LP that must be applied simultaneously in order to make a leaner organization (Tréville \& Antonakis, 2006). Regardless the fact that LP have been used for years, there is little evidence of generalizable steps of lean implementation (Marodin \& Saurin, 2013; Tortorella et al., 2015). Pavnaskar et al. (2003) complemented that the main reasons for lean implementation failures can be associated with misinterpretation in the intensity and way LP are adopted.

From an analysis of the literature on LH, we have listed some of the most cited LP in healthcare as shown in Table 1. Among these, 'value stream mapping', 'visual management' and 'operation standardization' appear in

Table 1. Citation frequence of LP in the literature.

\begin{tabular}{|c|c|c|c|c|c|c|c|c|c|c|c|c|c|c|c|c|c|c|c|c|c|c|c|c|c|c|c|}
\hline $\mathrm{LP}$ & 1 & 2 & 3 & 4 & 5 & 6 & 7 & 8 & 9 & 10 & 11 & 12 & 13 & 14 & 15 & 16 & 17 & 18 & 19 & 20 & 21 & 22 & 23 & 24 & 25 & 26 & $\mathrm{~N}^{\circ}$ \\
\hline $\begin{array}{l}I p_{1}-\text { Value stream } \\
\text { mapping }\end{array}$ & & $x$ & $x$ & & & & & $X$ & & $X$ & & & $x$ & $x$ & $\mathrm{X}$ & & & & & & & $x$ & & $x$ & $X$ & & 10 \\
\hline $\begin{array}{l}I p_{2}-\text { Visual } \\
\text { management }\end{array}$ & & & & & $x$ & & $x$ & $x$ & $x$ & & & & $x$ & $x$ & & $x$ & $x$ & $x$ & & & $x$ & & & & & & 10 \\
\hline $\begin{array}{l}I p_{3}-\text { Operation } \\
\text { standardization }\end{array}$ & $x$ & & & & $x$ & & & & & $x$ & & & & $x$ & & & $x$ & $x$ & & $x$ & & $x$ & & & $x$ & $x$ & 10 \\
\hline $\begin{array}{l}I p_{4}-\text { Continuous } \\
\text { flow }\end{array}$ & & & $x$ & & & & $x$ & $x$ & & $x$ & $x$ & & & $x$ & & & & & & & & & & & & & 6 \\
\hline$I p_{5}-$ Pull system & & $x$ & & & & & & $x$ & & & $x$ & & & & & & & & $x$ & & & $x$ & $x$ & & & & 6 \\
\hline$I p_{6}-5 S$ & & & & & $x$ & & & $x$ & & & & & $x$ & & & & & & & $x$ & $x$ & & & $x$ & & & 6 \\
\hline$I p_{7}$ - Kaizen & & & & & & & $x$ & & & & & & & & $x$ & & $x$ & $x$ & & $x$ & $x$ & & & & & & 6 \\
\hline $\begin{array}{l}I p_{8}-\text { Problem } \\
\text { solving } \\
\text { methodology }\end{array}$ & & & & $x$ & $x$ & $x$ & & & $x$ & & & & & $x$ & & & & $x$ & & & & & & & & & 6 \\
\hline $\begin{array}{l}I p_{9} \text { - Production } \\
\text { leveling }\end{array}$ & & & & & & & & & & & $x$ & & & & $x$ & & & & $x$ & & & & $x$ & & & $x$ & 5 \\
\hline$I p_{10}-$ Gemba walk & & & & $x$ & & $x$ & & & $x$ & & & & & & & & & $x$ & & & & & & & $\mathrm{X}$ & & 5 \\
\hline $\begin{array}{l}I p_{11^{-}} \\
\text {Crossfunctional } \\
\text { team }\end{array}$ & $x$ & & & & & & & $x$ & & & & & & & & $x$ & & & & & & $x$ & & & & & 4 \\
\hline $\begin{array}{l}I p_{12}-\text { Error-proof } \\
\text { systems }\end{array}$ & & & & & & & & & & & & & & & & & $x$ & & & & $x$ & & & $x$ & $x$ & & 4 \\
\hline $\begin{array}{l}I p_{13} \text { - Operations } \\
\text { balance }\end{array}$ & $x$ & & & & & & & & & & & & & & & & & & & $x$ & & & & $x$ & & $x$ & 4 \\
\hline $\begin{array}{l}I p_{14}-\text { Workplace } \\
\text { design }\end{array}$ & & & & & & & $x$ & & & & & & & & & $x$ & & & & & & & & & & & 2 \\
\hline$I p_{15}-$ Kanban & & & & & & & & & & & $x$ & & & & & $x$ & & & & & & & & & & & 2 \\
\hline $\begin{array}{l}I p_{16}-\text { Setup } \\
\text { reduction }\end{array}$ & $x$ & & & & & & $x$ & & & & & & & & & & & & & & & & & & & & 2 \\
\hline$I p_{17}-$ Andon & & & & & & & $x$ & & $x$ & & & & & & & & & & & & & & & & & & 2 \\
\hline $\begin{array}{l}I p_{18}-\text { Training/ } \\
\text { education }\end{array}$ & & & & & & & & & & & & & & & & $x$ & & & & & & $x$ & & & & & 2 \\
\hline $\begin{array}{l}I p_{19} \text { - Total } \\
\text { productive } \\
\text { maintenance }\end{array}$ & & & & & & & & & & & & & & & & & & $x$ & & & & & & & & & 1 \\
\hline $\begin{array}{l}l p_{20^{-}} \\
\text {Autonomation } \\
\text { (Jidoka) }\end{array}$ & & & & & & & & & & & & & & & & & $x$ & & & & & & & & & & 1 \\
\hline $\begin{array}{l}I p_{21}-\text { Workforce } \\
\text { empowerment }\end{array}$ & & & & & & & & & & & & $x$ & & & & & & & & & & & & & & & 1 \\
\hline $\begin{array}{l}I p_{22}-\text { Small batch } \\
\text { sizes }\end{array}$ & & & & & & & & & & & $x$ & & & & & & & & & & & & & & & & 1 \\
\hline
\end{tabular}

Authors: 1- Leslie et al. (2006); 2- Lummus et al. (2006); 3- Persoon et al. (2006); 4- Shannon et al. (2006); 5- Ballé \& Régnier (2007); 6- Braaten \& Bellhouse (2007); 7- Bush (2007); 8- Fillingham (2007); 9- Furman \& Caplan (2007); 10- Kim et al. (2007); 11- Zarbo \& D’Angelo (2007); 12- Dickson et al. (2009); 13- Esain et al. (2008); 14- Raab et al. (2008); 15- Casey et al. (2009); 16- Zarbo et al. (2009); 17- Grout \& Toussaint (2010); 18- Kimsey (2010); 19- Rechel et al. (2010); 20- Waldhausen et al. (2010); 21- Souza \& Pidd (2011); 22- Laganga (2011); 23- Carvalho et al. (2013); 24- Laureani et al. (2013); 25- Bhat et al. (2014); 26- Gijo \& Antony (2014). 
10 out of 26 research papers. According to Augusto \& Tortorella (2017), these practices require few adaptations when used in healthcare when compared to manufacturing environments and, therefore, this would be one of the reasons for their wider dissemination in the literature. On the other hand, practices 'total productive maintenance', 'autonomation', 'workforce empowerment' and 'small batch size' presented the lowest frequency of citation.

\subsection{CSF for lean implementation}

Several studies were carried out with the purpose of listing the CSF for lean implementation. Liker (2004) describes 14 principles that guide the Toyota Production System and divides them into four categories: (i) philosophy; (ii) processes; (iii) employees and partners; and (iv) problem solving. Poksinska (2010) lists five problems encountered when starting $\mathrm{LH}$ implementation: employee resistance, lack of trained employees, lack of a clear customer focus, highly verticalized hierarchical structure and exclusively departmental improvement focus. In a complementary way, Young \& McClean (2008) identified three critical problems that impair the expansion of the LP application in healthcare: $(i)$ uncertainty level inherent to healthcare (e.g. difficulty in demand predictability and determination of process times); (ii) defining activities that add value; and (iii) conflicting and disconnected metrics.

In this sense, SAE J4000 standard, which comprises 52 items, is an instrument that aims to identify and measure best practices in a lean implementation (Society of Automotive Engineers, 1999). Vinodh et al. (2011) and Vinodh \& Chintha (2011) used the AHP (Analytic Hierarchy Process) to evaluate a lean implementation based on a review of the literature and experts' opinions from manufacturing organizations. Achanga et al. (2006) identified four CSF for implementing LM in small and medium-sized enterprises; they are: (i) leadership and management; (ii) finance; (iii) skills and knowledge; and (iv) organizational culture. The model proposed by Dahlgaard et al. (2011) aims to evaluate healthcare organizations with regards to their problems and results. The model is composed of five criteria: ( $i$ ) leadership; (ii) people management; (iii) partnerships and resources; (iv) processes; and $(v)$ results. Finally, the evaluation of Shingo Prize (2014) is composed by 10 principles grouped into four dimensions: (i) cultural enablers; (ii) continuous improvement process; (iii) organization alignment; and (iv) results.

Based on the studied authors in Table 2, we consolidate the main CSF to be reinforced throughout the lean implementation. In total, five critical factors were consolidated: (i) people; (ii) partnerships/resources; (iii) services/results; ( $i v$ ) processes and ( $v$ ) leadership. Such consolidation will serve as a basis for establishing the relationship between the $\mathrm{LP}$ and CSF.

Table 2. Consolidation of CSF for lean implementation.

\begin{tabular}{|c|c|c|c|c|c|c|}
\hline $\begin{array}{l}\text { SAE J4000 (Society of } \\
\text { Automotive Engineers, } \\
\text { 1999): } \\
5 \text { Elements }\end{array}$ & $\begin{array}{l}\text { Liker (2004): } \\
4 \text { Categories }\end{array}$ & $\begin{array}{l}\text { Achanga et al. } \\
\text { (2006): } \\
4 \text { CSF }\end{array}$ & $\begin{array}{l}\text { Vinodh et al. } \\
\text { (2011): } \\
5 \text { Enablers }\end{array}$ & $\begin{array}{c}\text { Dahlgaard et al. } \\
\text { (2011): } \\
5 \text { Criteria }\end{array}$ & $\begin{array}{l}\text { Shingo Prize } \\
\text { (2014): } \\
\text { 4 Dimension }\end{array}$ & $\begin{array}{c}\text { CSF for lean } \\
\text { implementation }\end{array}$ \\
\hline $\begin{array}{l}\text { 1. Personnel } \\
\text { 2. Supplier/ Organization/ } \\
\text { Customer }\end{array}$ & $\begin{array}{l}\text { 1. Employees and } \\
\text { partners }\end{array}$ & & 1. Workforce & $\begin{array}{l}\text { 1. Personnel } \\
\text { 2. Partners/ } \\
\text { Resources }\end{array}$ & & $\begin{array}{l}\mathrm{CSF}_{1} . \text { People } \\
\mathrm{CSF}_{2} . \text { Partners/ } \\
\text { Resources }\end{array}$ \\
\hline 3. Product & & 1. Finance & & $\begin{array}{l}\text { 3. Products/ } \\
\text { Results }\end{array}$ & 1. Results & $\begin{array}{l}\mathrm{CSF}_{3} . \text { Services/ } \\
\text { Results }\end{array}$ \\
\hline 4. Process/ Information flow & $\begin{array}{l}\text { 2. Problem } \\
\text { solving } \\
\text { 3. Process }\end{array}$ & $\begin{array}{l}\text { 2. Skills and } \\
\text { knowledge }\end{array}$ & $\begin{array}{l}\text { 2. Manufacturing } \\
\text { strategy } \\
\text { 3. Technology }\end{array}$ & 4. Process & $\begin{array}{l}\text { 2. Continuous } \\
\text { improvement } \\
\text { process }\end{array}$ & $\mathrm{CSF}_{4}$. Process \\
\hline $\begin{array}{l}\text { 1. } 5 \text {. Administration/ } \\
\text { responsibility }\end{array}$ & 4. Philosophy & $\begin{array}{l}\text { 3. Leadership and } \\
\text { management } \\
\text { 4. Organizational } \\
\text { culture }\end{array}$ & $\begin{array}{l}\text { 4. Management } \\
\text { responsibility } \\
\text { 5. Production } \\
\text { administration }\end{array}$ & 5. Leadership & $\begin{array}{l}\text { 3. Organization } \\
\text { alignment } \\
\text { 4. Cultural } \\
\text { enablers }\end{array}$ & $\mathrm{CSF}_{5}$. Leadership \\
\hline
\end{tabular}

\section{Method}

The proposed methodology, comprised of six steps, is shown in Figure 1. The first step comprises the construction of the relationship matrix between the $22 \mathrm{LP}$ (Table 1) and the 5 CSF (Table 2) using the Delphi method. To this end, the selection of experts was comprised of two criteria: $(i)$ minimum of 10 years of practical and academic experience in lean implementation; and (ii) participation as authors in specific journals of the 


\begin{tabular}{cll}
\hline Step & & \multicolumn{1}{c}{ Description } \\
\hline 1 & Construction of relationship matrix and importance index of LP & Method \\
2 & Identification of problems' occurrence frequency in a healthcare organization & Questionnaire (Dahlgaard et al., 2011) \\
3 & Verification of LP implementation level in the healthcare organization & Semi-structured interviews \\
4 & Determination of criticity index of LP in the healthcare organization & Maturity matrix (Tortorella and Fogliatto, 2014) \\
5 & Multicriteria analysis for prioritising LP implementation & Multiattribute Utility (MAUT) \\
6 & Ranking of LP for LH implementation & Graphical tools \\
\hline
\end{tabular}

Figure 1. Proposed method.

correlated areas. Initially, 18 (eighteen) experts were invited to participate in the study, of which only 6 (six) effectively participated in all steps due to agenda availability. The definition of the number of rounds to be carried out depended on obtaining an acceptable consensus level. The consensus was measured based on the variation coefficient. According to Giovinazzo (2001), an acceptable value to denote consensus must be lower than 30\% for this variation coefficient. Since 110 relationships were analyzed, the final consensus was calculated as the number of items with variation coefficient below 30\% divided by the total number of items. A value greater than $90 \%$ was adopted as an acceptable final consensus. Consequently, two rounds of the method were performed, making it possible to reach a final consensus of 91\%.

Subsequently, an initial evaluation of the relationship intensities between each pair of LP and CSF was requested by e-mail to the experts, accompanied by an explanatory letter clarifying the importance of participation in the research, the objectives of the research and the proposed model. In this round, experts should answer the following question: "for lean implementation in healthcare, how does practice $i$ impact the critical factor $j$ ?". It is noteworthy that at the beginning of each email, a brief explanation providing a uniform definition of each one of the $\mathrm{LH}$ practices and critical success factors was undertaken. According to Kothari (2004), such explanation may avoid misinterpretations among experts, mitigating erroneous values and responses. The evaluation was measured based on a scale from 1 to 9 , where 1 denotes a 'non-existent' impact and 9 an 'absolutely important'. The experts' responses were returned by e-mail and consolidated. In the second round, the same experts had the information on the absolute frequency distribution of the answers sent by the others, as well as their own answers, leading to a reflection on his answers. The comments for each question were also made available for all experts, without authors' identification.

From the experts' answers, a structure called relationship matrix (M), schematized in Figure 2, was established, which shows the relationship intensity $r_{\mathrm{ij}}$ rescaled into an interval from 0 to 1 for each pair of LP and CSF at the intersections between lines and columns. The results of matrix $M$ are measured through an importance index for $\mathrm{LP}\left(i p_{\mathrm{i}}\right)$, which represents the relevance of the practice for the implementation of $\mathrm{LH}$, considering the sum of the relationship intensities of relationship of the practice for each CSF by means of the following expression:

$$
i p_{i}=\sum_{j=1}^{5} r_{i j}, i=1, \ldots, 22
$$

\begin{tabular}{|c|c|c|c|c|c|c|c|c|c|c|}
\hline \multirow{2}{*}{ LP } & \multirow{2}{*}{$\begin{array}{l}\text { Gap for } \\
\text { full } \\
\text { adoption } \\
\text { of LP }\end{array}$} & \multicolumn{5}{|c|}{$\begin{array}{l}\text { Critical success factors for lean } \\
\text { implementation }\end{array}$} & \multirow{2}{*}{$\begin{array}{l}\text { Importance } \\
\text { of LP }\end{array}$} & \multirow{2}{*}{$\begin{array}{l}\text { Importance } \\
\text { diff. index }\end{array}$} & \multirow{2}{*}{$\begin{array}{l}\text { Criticity of } \\
\text { LP }\end{array}$} & \multirow{2}{*}{$\begin{array}{c}\text { Criticity } \\
\text { diff. } \\
\text { index }\end{array}$} \\
\hline & & $\mathrm{CSF}_{1}$ & $\mathrm{CSF}_{2}$ & $\mathrm{CSF}_{3}$ & $\mathrm{CSF}_{4}$ & $\mathrm{CSF}_{5}$ & & & & \\
\hline$l p_{1}$ & $g_{1}$ & & & & & & $i p_{1}$ & $i d_{1}$ & $c_{1}$ & $i c_{1}$ \\
\hline$\vdots$ & $\vdots$ & & & $r_{i j}$ & & & $\vdots$ & $\vdots$ & $\vdots$ & $\vdots$ \\
\hline$l p_{22}$ & $g_{22}$ & & & & & & $i p_{22}$ & $i d_{22}$ & $c_{22}$ & $i c_{22}$ \\
\hline
\end{tabular}

\begin{tabular}{ccccccc}
$\begin{array}{c}\text { Frequency of } \\
\text { problems }\end{array}$ & $p_{1}$ & $p_{2}$ & $p_{3}$ & $p_{4}$ & $p_{5}$ \\
\hline
\end{tabular}

Figure 2. Representation of matrix M. 
In step (ii), there is the identification of the occurrence frequency of problems in the healthcare organization through the application of a questionnaire. The proposed questionnaire is an adaptation of the method developed by Dahlgaard et al. (2011), which lists 50 issues grouped according to each CSF (see Appendix A). The questionnaire was answered by employees with at least 6 months of experience in the organization under study. For each CSF there are 10 questions sequentially associated and evaluated through a likert scale from 1 to 5 , where 1 designates a situation that almost never occurs and 5 a situation that almost always occurs. Based on the answers, a mean value of frequency is established for each question and these are rescaled into an interval from 0 to 1 , represented by $f_{\mathrm{k}}(k=1, \ldots, 50)$. Due to the way that the questions were elaborated, a high value of $f_{\mathrm{k}}$ reinforces a desirable condition. Consequently, the occurrence frequency of problems is given by $f p_{k}$ through Equation 2. Therefore, the occurrence frequency of problems in each of the five CSF, represented by $p_{\mathrm{j}}(j=1, \ldots, 5)$, is given by the mean of the respective $f p_{\mathrm{k}}$ associated.

$$
f p_{k}=1-f_{k}, k=1, \ldots, 50
$$

For surveying the implementation level of the $22 \mathrm{LP}$ in the healthcare organization, a second questionnaire was applied with the same employees of the department under study. Before the beginning of each interview, a brief explanation providing a uniform definition of each one of the LP was undertaken. Respondents were invited to assess the implementation level of LP based on a Likert scale from 1 to 5 , where 1 denotes a practice that is almost never applied and 5 a practice that is fully adopted. Based on the answers, an average level of implementation is established for each $\mathrm{LP}$ and these are rescaled into a 0 to 1 range, represented by $n_{\mathrm{i}}(i=1, \ldots, 22)$. The gap for the full adoption of each LP in the healthcare organization, represented by $g_{\mathrm{i}}$, is given by the following expression:

$$
g_{i}=1-n_{i}, i=1, \ldots, 22
$$

At step ( $i v$ ) the values of $p_{\mathrm{j}}$ and $g_{\mathrm{j}}$ are used for determining the criticality indices of LP, whose values are inserted in matrix M. The degree of criticality of LP integrates both theoretical and contextual relevance for the lean implementation. The establishment of the criticality indices provides managers of the healthcare organization basis for improving their processes. Thus, the criticality index $c_{i}$ is given by the following expression:

$$
c_{i}=g_{i} x \sum_{j=1}^{5} r_{i j} x p_{j}, i=1, \ldots, 22
$$

To better compare the values of importance and criticality of LP, a differentiation index was created representing the number of standard deviations of each individual value of importance and criticality in relation to the average of all practices' values. Such differentiation index allows the removal of scale effects. High positive values of this index indicate the most important and critical LP. For the purpose of this work, the value of 1.0 standard deviation above the average was considered as a threshold value to denote the relevance of the practice (Tortorella et al., 2017b).

Step $(v)$ corresponds to the multicriteria analysis to prioritize the LP implementation efforts. The evaluation of the LP to be prioritized in the healthcare organization consists in investigating its characteristics under real conditions of time, space and information, and according to available resources. Therefore, a proper decision process under this scenario should be supported by multicriteria decision making methods. At this step, senior leaders of the healthcare organization are asked to participate in the decision-making process by establishing criteria and attributes that allow the company to take into account its cultural and organizational characteristics and urgency for improvement.

To evaluate the distinctions between the attributes, a Multiattribute Utility (MAUT) was used to consider opportunities for improvement. The first criterion assesses LP in relation to the importance of implementation and is subdivided into three main attributes (Tortorella \& Fogliatto, 2014): (i) achievement of strategic goals; (ii) behavioral construction consistent with organizational values; and (iii) impact on organizational structure. The second criterion evaluates LP in relation to the implementation effort, and consists of three attributes: ( $i$ ) technical risk; (ii) the need for training; and (iii) the need for investment. From the multi-attribute structure, the organization's managers are asked to assign importance to the attributes and criteria, on a scale from 0 to 100, with 100 being the maximum importance value. The declared amounts are then rewritten in percentage terms, generating the weights $\left(p a_{\mathrm{m}}, m=1, \ldots, 6\right)$.

Then, to prioritize LP implementation efforts a prioritization matrix (Z) was used, as shown in Figure 3. The $\mathrm{LP}$ are listed in the lines with their respective criticality values $\left(c_{i}\right)$. In the columns of the matrix there are the attributes for prioritizing $\mathrm{LP}$, which were previously identified and weighted. Leaders were asked to determine the 


\begin{tabular}{|c|c|c|c|c|c|c|c|c|}
\hline \multirow[b]{2}{*}{ LP } & \multicolumn{3}{|c|}{ Importance for organization } & \multicolumn{3}{|c|}{ Effort for implementation } & \multirow[b]{2}{*}{$\begin{array}{l}\text { Criticity } \\
\text { of LP }\end{array}$} & \multirow[b]{2}{*}{$\begin{array}{l}\text { Implementation } \\
\text { priority }\end{array}$} \\
\hline & $\begin{array}{c}\text { Achievement } \\
\text { of strategic } \\
\text { goals } \\
p a_{l}\end{array}$ & $\begin{array}{c}\text { Construction } \\
\text { of coeherent } \\
\text { behaviors } \\
p a_{2}\end{array}$ & $\begin{array}{c}\text { Impact on } \\
\text { organizational } \\
\text { structure } \\
p a_{3}\end{array}$ & $\begin{array}{c}\text { Technical } \\
\text { risk } \\
\mathrm{pa}_{4}\end{array}$ & $\begin{array}{c}\text { Need for } \\
\text { training } \\
\quad p a_{5}\end{array}$ & $\begin{array}{c}\text { Need for } \\
\text { investment } \\
\quad p a_{6}\end{array}$ & & \\
\hline$l p_{1}$ & & & & & & & $\bar{c}$ & $z_{1}$ \\
\hline$\vdots$ & & & $p d_{i m}$ & & & & $\vdots$ & $\vdots$ \\
\hline$l p_{22}$ & & & & & & & $c_{22}$ & $z_{22}$ \\
\hline
\end{tabular}

Figure 3. Representation of priority matrix Z.

degree of relationship of each LP with the attributes, expressed by $p d_{\text {im }}(j=1, \ldots, 22 ; m=1, \ldots, 6)$. Thus, each company leader was asked the following questions: ( $i)$ for the attributes related to the criterion importance for organization, "what is the importance of practice $i$ in the accomplishment of the attribute $m$ ?". The evaluation is performed through a scale of three values: 9 (strong relationship), 3 (moderate relationship) and 1 (weak relationship); and (ii) for the attributes related to the criterion effort for implementation, "what is the impact of the practice $i$ on the attribute $m$ ?". Because the attributes of this criterion reinforce an undesirable aspect (e.g. greater technical risk, more training or higher investment) in the organization, and to maintain consistency in the attribute rating scale (higher-is-better), a high value is a favorable condition. Thus, specifically for these attributes, the evaluation is carried out by means of a scale of three values, being: 9 (low impact), 3 (moderate impact) and 1 (high impact). The absence of impact is represented by the value 0 . Thus, the implementation priority $\left(z_{\mathrm{j}}\right)$ is given by:

$$
z_{i}=\sum_{m=1}^{6}\left(p d_{i m} x p a_{m}\right) c_{i}, i=1, \ldots, 22
$$

The last step $(v i)$ is the ranking of practices for $\mathrm{LH}$ implementation, whose values of $z_{\mathrm{i}}$ were ordered. To help visualize the prioritized LP and facilitate decision making, it is recommended to use graphical tools, such as the Pareto chart.

\section{Case study}

\subsection{Emergency Department (ED) of a Brazilian public hospital}

The proposed methodology was applied in the Emergency Department (ED) of a Brazilian public hospital integrated into the healthcare network of the SUS. In this sense, there are great budgetary constraints regarding the implementation of new processes and technologies. The primary ambulatory care of the hospital is structured in four basic areas: medical, surgical, pediatrics and gynecology. These areas attend 250 patients per day in average and are supported by a determined infrastructure (Table 3). Historically, few formal LH implementation initiatives have been demonstrated in the hospital. However, some of the LP practices are developed in isolation even without their in-depth knowledge. Among them, the practices of poka-yoke, which is applied to differentiate materials that can generate risks to the employees, and jidoka, stand out, since most of the equipment is programmed with devices to stop in case of any problem. Overall, LH is still poorly understood and widespread among emergency and hospital staff.

In particular, the study was restricted to the context of the ED, due to the greater flow of patients (approximately 250 patients per day) and the range of specialties with which the department operates. The function of the ED is to provide treatment to those in need of urgent medical intervention, aiming to stabilize the patient and reach a minimally satisfactory level of care, so as to be able to safely address the patient to the next step in the process. ED's team is comprised of 21 doctors, 18 nurses and 71 technicians and nursing residents, totaling 110 employees, which are divided into three working shifts, being the first shift from 7:00 a.m. to 1:00 p.m., the second from 1:00 p.m. to 7:00 p.m. and the third from 7:00 p.m. to 7:00 a.m.

When patients arrive at ED, they undergo a first risk classification. The most critical cases are denoted as 'red-emergency' cases and receive immediate care. In these cases, family members are responsible for completing the initial attendance sheet. For other patients, it is necessary to fill out this form at the reception. After this 
Table 3. ED's infrastructure.

\begin{tabular}{cc}
\hline & Quantity \\
\hline Attendance / Day & 250 \\
Medical offices & 5 \\
Stretchers Macas & 8 \\
Beds & 12 \\
X-Ray room & 1 \\
Warehouse & 1 \\
Pharmacy & 1 \\
Surgical rooms & 2 \\
Insulation beds & 1 \\
Resuscitation beds & 2 \\
Ambulatory procedure room & 1 \\
Sorting room & 1 \\
Equipments room & 1 \\
\hline
\end{tabular}

step, the patient is directed to a risk assessment, in which a nurse performs an evaluation, collects his/her vital data and classifies it according to the urgency of medical care, following the Vancouver protocol. The existing classifications for prioritizing medical care are: orange (very urgent), yellow (urgent), green (not urgent) and blue (non-urgent). After the medical care has been performed, the patient can be directed to beds or other rooms according to the medical need, or even be dispensed.

\subsection{Identify the occurrence frequency of problems}

Thus, it was sought to identify the occurrence frequency of problems and the implementation level of $\mathrm{LP}$ in this context. In this sense, different employees from different hierarchical levels of the ED were invited to answer the two questionnaires described in section 3. Data collection was performed over a period of two months. The sample of respondents comprises a total of 30 individuals, which represents approximately 27\% of the total employees in the department (see Table 4). Most of the respondents were technicians and nursing residents, who presented an average working time of 6 years in the ED. Nurses, in turn, correspond to 27\% of the respondents and have an average working time of 3 years. Finally, physicians represent $13 \%$ of the sample, with 10 months as the average working time in the ED.

Table 4. Characteristics of respondents.

\begin{tabular}{cccc}
\hline Role & Number of respondents & $\%$ & Average time in the department \\
\hline Doctor & 4 & $13 \%$ & 10 months \\
Nurse & 8 & $27 \%$ & 3 years \\
Nursury assistant and technician & 18 & $60 \%$ & 2 years \\
Total & 30 & & \\
\hline
\end{tabular}

To identify the occurrence frequency of problems, each employee answered the 50 questions and, based on their answers, an average value of frequency was established for each question. The incidence frequency of problems in each of the five CSF, represented by $p_{\mathrm{j}}(j=1, \ldots, 5)$, is given by the mean of the respective $f p_{k}$ associated. The higher the value obtained for $p$, the greater will be the occurrence frequency of problems related to the respective CSF. Thus, it can be verified that problems related to $\mathrm{CSF}_{2}$ (People Management) are the most frequent according to repondents' perception in the ED.

\subsection{Relationship intensities among the CSF and LP}

Regarding the implementation level of LP, each employee assigned an implementation score to the $22 \mathrm{LP}$ and, based on their responses, an average implementation value was established for each LP. After that, values were rescaled into an interval from 0 to 1 , obtaining values for $n_{\mathrm{i}}$ and values for $g_{\mathrm{i}}(i=1, \ldots, 22)$, which represent 
the gap for the full adoption of $\mathrm{LP}$ in the ED. From the data collected, practice $\mathrm{LP}_{15}$ (Kanban) appears to have the highest potential $\left(g_{15}=0.68\right)$ for implementation in the department (see Appendix B).

The relationship intensities among the CSF and LP were consolidated and the importance index of each LP was obtained according to the maturity matrix $\mathrm{M}$ (see Table 5). According to established threshold value, five $\mathrm{LP}$ showed differentiation indexes above 1.0; they are: $I p_{7}$ (Kaizen), $l p_{8}$ (Problem solving methodology), $I p_{2}$ (Visual management), $I p_{11}$ (Crossfunctional teams) and $I p_{18}$ (Education/training). Then, based on the occurrence frequency of problems and implementation level of LP, the criticality values for each LP was determined. The higher the value obtained for $c_{i}$, the more critical is the $\mathrm{LP}$ for the $\mathrm{LH}$ implementation in the ED. Similar to the importance index, practices whose differentiation indexes for criticality presented values above 1.0 were $I p_{7}, I p_{8}, I p_{2}$ and $I p_{15}$.

Table 5. Maturity matrix M.

\begin{tabular}{|c|c|c|c|c|c|c|c|c|c|c|}
\hline $\mathrm{LP}$ & $\begin{array}{c}\text { Gap for full } \\
\text { adoption of LP }\end{array}$ & $\mathrm{CSF}_{1}$ & $\mathrm{CSF}_{2}$ & $\mathrm{CSF}_{3}$ & $\mathrm{CSF}_{4}$ & $\mathrm{CSF}_{5}$ & $\begin{array}{l}\text { Importance } \\
\text { of LP }\end{array}$ & $\begin{array}{l}\text { Importance } \\
\text { diff. index }\end{array}$ & $\begin{array}{l}\text { Criticity } \\
\text { of LP }\end{array}$ & $\begin{array}{l}\text { Criticity } \\
\text { diff. index }\end{array}$ \\
\hline$l p_{1}$ & 0.48 & 1.0 & 0.8 & 0.8 & 1.0 & 0.9 & 4.4 & 0.6 & 1.1 & 0.5 \\
\hline$l p_{2}$ & 0.52 & 1.0 & 1.0 & 0.9 & 0.9 & 0.9 & 4.7 & 1.2 & 1.2 & 1.1 \\
\hline$l p_{3}$ & 0.36 & 0.9 & 0.9 & 0.8 & 1.0 & 0.8 & 4.3 & 0.4 & 0.8 & -1.0 \\
\hline$l p_{4}$ & 0.40 & 0.8 & 0.8 & 0.8 & 0.9 & 0.8 & 4.0 & -0.5 & 0.8 & -0.9 \\
\hline$l p_{5}$ & 0.54 & 1.0 & 0.7 & 0.8 & 1.0 & 0.8 & 4.2 & 0.1 & 1.1 & 0.7 \\
\hline$l p_{6}$ & 0.51 & 0.9 & 0.9 & 0.9 & 0.9 & 0.8 & 4.3 & 0.4 & 1.1 & 0.6 \\
\hline$l p_{7}$ & 0.57 & 1.0 & 1.0 & 0.9 & 1.0 & 1.0 & 4.9 & 1.8 & 1.4 & 2.0 \\
\hline$l p_{8}$ & 0.53 & 1.0 & 0.9 & 0.9 & 1.0 & 1.0 & 4.8 & 1.5 & 1.3 & 1.4 \\
\hline$l p_{9}$ & 0.43 & 0.9 & 0.7 & 0.7 & 0.9 & 0.8 & 3.9 & -0.8 & 0.9 & -0.7 \\
\hline$l p_{10}$ & 0.54 & 1.0 & 0.9 & 0.8 & 0.8 & 0.8 & 4.2 & 0.1 & 1.2 & 0.8 \\
\hline$l p_{11}$ & 0.25 & 1.0 & 1.0 & 0.9 & 1.0 & 0.8 & 4.7 & 1.2 & 0.6 & -2.1 \\
\hline$l p_{12}$ & 0.39 & 0.9 & 0.8 & 0.8 & 0.8 & 0.8 & 4.0 & -0.5 & 0.8 & -1.0 \\
\hline$l p_{13}$ & 0.45 & 0.8 & 0.7 & 0.8 & 0.9 & 0.9 & 4.0 & -0.5 & 0.9 & -0.5 \\
\hline$l p_{14}$ & 0.45 & 0.7 & 0.7 & 0.8 & 0.8 & 0.8 & 3.7 & -1.4 & 0.8 & -0.8 \\
\hline$l p_{15}$ & 0.68 & 0.7 & 0.7 & 0.8 & 0.9 & 0.8 & 3.8 & -1.1 & 1.3 & 1.5 \\
\hline$l p_{16}$ & 0.48 & 0.8 & 0.7 & 0.7 & 0.8 & 0.8 & 3.7 & -1.4 & 0.9 & -0.5 \\
\hline$l p_{17}$ & 0.46 & 0.9 & 0.9 & 0.8 & 0.9 & 0.9 & 4.3 & 0.4 & 1.0 & 0.1 \\
\hline$l p_{18}$ & 0.35 & 1.0 & 1.0 & 0.9 & 0.9 & 0.9 & 4.7 & 1.2 & 0.8 & -0.8 \\
\hline$l p_{19}$ & 0.53 & 0.8 & 0.7 & 0.8 & 0.9 & 0.8 & 3.9 & -0.8 & 1.0 & 0.2 \\
\hline$l p_{20}$ & 0.45 & 0.8 & 0.8 & 0.8 & 0.9 & 0.8 & 4.0 & -0.5 & 0.9 & -0.4 \\
\hline$l p_{21}$ & 0.44 & 1.0 & 1.0 & 0.8 & 0.9 & 0.8 & 4.4 & 0.7 & 1.0 & 0.0 \\
\hline$l p_{22}$ & 0.49 & 0.8 & 0.7 & 0.7 & 0.9 & 0.8 & 3.8 & -1.1 & 0.9 & -0.3 \\
\hline \multicolumn{2}{|c|}{ Frequency of problems } & 0.49 & 0.54 & 0.49 & 0.51 & 0.50 & & & & \\
\hline
\end{tabular}

\subsection{LP assessment}

It is worth noticing that practices $l p_{2}, l p_{7}$ and $l p_{8}$ stand out both in terms of theoretical importance (experts' opinion) and in terms of contextual criticality for the ED. The department under study is composed by diverse and complex flows that need more efficient ways of monitoring. All patient information is attached to the patient's chart and there is no method to track patient status or other kind of information. Besides supporting a better flow visualization, practice $I p_{2}$ allows to streamline the reaction process (Liker, 2004; Fillingham, 2007), enabling a more immediate identification of anomalies occurrence. Thus, the adoption of this practice helps to minimize misinterpretations throughout the processes, making the flow of value more efficient and assertive.

Practice $l p_{7}$ consists of continuous improvement activities inherent to lean implementation. Specifically in healthcare, this practice is more commonly understood as short-term events driven by crossfunctional teams (kaizen events), through which problems are identified and the necessary improvements are implemented (Souza, 2009). Since no initiative related to this practice was identified in the department under study, the high adoption potential perceived by the employees $\left(g_{7}=0.57\right)$ is justified. Thus, this result corroborates with the 
studies developed by Dickson et al. (2009) and Bush (2007), which exemplify the LH implementation through kaizen events.

Similarly, $I p_{8}$ has a wide scope of application and can be adapted according to the severity and type of problems identified. Previous studies focused on the LM (e.g. Spear, 2004, 2009) indicate that the adoption level of this practice may denote a differentiation factor among organizations undergoing a lean implementation, since both the organization and its employees develop as it is implemented. Spear (2005) adds that LH seeks to make employees able to solve problems by teaching them how to deal with root causes of problems. In this sense, according to Mazzocato et al. (2010), this practice should involve leaders in order to provide guidance to employees and the creation of stable structures for solving problems. Although the ED presents small initiatives, the adoption of this practice does not involve the whole team; only the nursury participates in problem solving meetings and they are optional. Thus, during the ED's daily activities, the vast majority of problems are solved in a reactive and superficial manner, without the direct involvement of all responsible parties, and the root causes of the problems are not usually addressed.

On the other hand, not all practices deemed as important presented high criticality values. For instance, $l p_{11}$ (Crossfunctional teams) $\left(i p_{11}=4.7\right)$ presents as main benefit the utilization of knowledge and complementary perspectives of the individuals during the solution of problems and continuous improvement of the processes. Such complementarity allows holistic solutions to be obtained, avoiding punctual gains in the value stream. Zarbo et al. (2009) and Poksinska (2010) emphasized that organizing employees in crossfunctional teams helps to analyze the flow of patients and identify what does not add value, engaging them in problem solving and process improvement. However, these teams tend to work on improvement projects with limited duration, leading to the dismemberment of the team after the project ends (Laganga, 2011). As the potential for full adoption of this practice is low in the ED, since there are already initiatives prior to $\mathrm{LH}$, the criticality of this practice has been deflated by its implementation level.

The $I p_{18}$ (Education/training) appears as the fifth most important practice $\left(i p_{18}=4.7\right)$ for $\mathrm{LH}$ implementation in general. This result corroborates with Poksinska (2010), which indicates that the first step in LH is to train employees on the principles, methods, and practices applied in lean implementation. Similarly, Ben-Tovim et al. (2008) argued that employees training is critical to lean implementation by providing them the basic concepts and principles for establishing a critical mass of change agents. However, following the example of $l p_{11}$, the interviewed team realizes that this practice is already being disseminated in the ED, which reduces the criticality degree for the context under study. This perception can be attributed to the fact that the hospital is linked to the federal university, favoring the dissemination of knowledge and praising the need for continuous training of its employees.

A few practices were considered of minor importance for $\mathrm{LH}$ implementation, such as $I p_{15}$ (Kanban), $I p_{22}$ (Small batch size), $I p_{14}$ (Workplace design) and $I p_{16}$ (Setup reduction). Augusto \& Tortorella (2017) observed that the literature evidence of $I p_{15}$ and $l p_{16}$ in healthcare is significantly lower than in manufacturing environments, indicating the low frequency of application of such practices in healthcare. In turn, $I p_{15}$ has a high criticality value, although it has not been indicated as one of the most important by the experts. Since the stock control methods identified in the ED are typically manual and informal, the high value found for this practice's gap for full adoption $\left(g_{15}=0.68\right)$ is consistent. In addition, Mazzocato et al. (2010) identified only one healthcare study that approached improvements in setup time. Regarding practices $l p_{22}$ and $l p_{14}$, the few evidences found in the literature portray their use in a limited way, being only adopted in supporting activities, such as laboratories of clinical and pathological analysis (Zarbo \& D’Angelo, 2007; Zarbo et al., 2009).

\subsection{Analysis of the improvement opportunities}

After presenting the improvement opportunities, the leadership of the hospital was interviewed in order to establish the importance of the evaluation attributes forming the decision profile for prioritization of the improvements. In this sense, the responses of ten senior management members were consolidated and the decision support structure indicated that the criterion 'importance of LP' is responsible for $45 \%$ of the decision, while 'effort for implementation' represents 55\% of the decision. For the first criterion, the contribution of the attribute 'achievement of strategic goals' represents 36\% of the importance of the criterion. Regarding the second criterion, the attributes 'technical risk' and 'need for investment' each represent 35\% of the importance.

Then, leaders were invited to assess LP and determine the weights $p d_{\text {im }}$ for LP in relation to the $m$ attributes. Both the head of nursing and medical were interviewed to establish consensus in the attribution of such weights. Once $p d_{\mathrm{im}}$ weights were known and the weights of the attributes of the decision-making structure were determined, the final score of each LP for the ED was determined, as shown in the prioritization matrix 
$\mathrm{Z}$ in Table 6. In addition, Figure 4 organizes the practices in descending order of $z_{\mathrm{k}}$, allowing an immediate analysis of the improvement opportunities.

The results indicate that the practice $l p_{2}$ (Visual management) presents the highest priority value $\left(z_{2}=11.9\right)$. It is worth noticing that this practice also stands out in its values of importance and criticality. The leadership understands that its implementation has low technical risk and low investment need, hence justifying the use of visual management mechanisms to aid in the visualization of process flows and assertiveness. In addition, its adoption is characterized by low need for training, since it excels with simplicity of application and team's understanding.

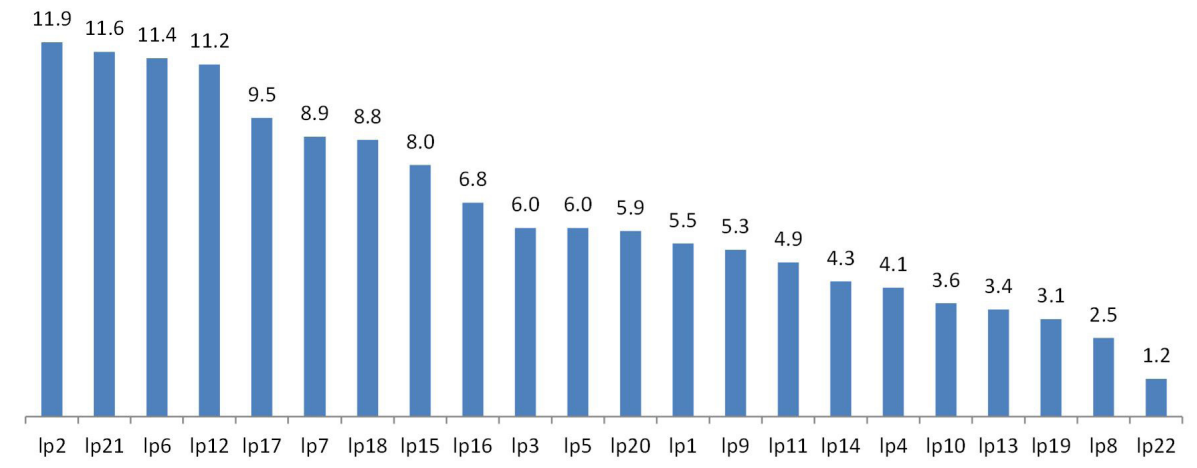

Figure 4. Ranking of LP.

Table 6. Prioritization matrix Z.

\begin{tabular}{|c|c|c|c|c|c|c|c|c|}
\hline \multirow{3}{*}{ LP } & \multicolumn{3}{|c|}{ Importance for organization } & \multicolumn{3}{|c|}{ Effort for implementation } & \multirow{3}{*}{$\begin{array}{l}\text { Criticity } \\
\text { of LP }\end{array}$} & \multirow{3}{*}{$\begin{array}{l}\text { Implementation } \\
\text { priority }\end{array}$} \\
\hline & $\begin{array}{c}\text { Achievement } \\
\text { of strategic } \\
\text { goals }\end{array}$ & $\begin{array}{c}\text { Construction } \\
\text { of coeherent } \\
\text { behaviors }\end{array}$ & $\begin{array}{c}\text { Impact on } \\
\text { organizational } \\
\text { structure }\end{array}$ & Technical risk & $\begin{array}{l}\text { Need for } \\
\text { training }\end{array}$ & $\begin{array}{l}\text { Need for } \\
\text { investment }\end{array}$ & & \\
\hline & $36 \%$ & $33 \%$ & $31 \%$ & $35 \%$ & $30 \%$ & $35 \%$ & & \\
\hline$I p_{1}$ & 1 & 3 & 9 & 0 & 3 & 0 & 1.1 & 5.5 \\
\hline$l p_{2}$ & 3 & 3 & 3 & 9 & 9 & 3 & 1.2 & 11.9 \\
\hline$l p_{3}$ & 3 & 3 & 3 & 3 & 1 & 9 & 0.8 & 6.0 \\
\hline$l p_{4}$ & 3 & 3 & 0 & 1 & 9 & 0 & 0.8 & 4.1 \\
\hline$l p_{5}$ & 3 & 3 & 1 & 1 & 9 & 0 & 1.1 & 6.0 \\
\hline$l p_{6}$ & 1 & 3 & 0 & 9 & 9 & 9 & 1.1 & 11.4 \\
\hline$l p_{7}$ & 0 & 1 & 3 & 9 & 3 & 3 & 1.4 & 8.9 \\
\hline$l p_{8}$ & 0 & 3 & 0 & 0 & 3 & 0 & 1.3 & 2.5 \\
\hline$I p_{9}$ & 0 & 0 & 0 & 9 & 9 & 0 & 0.9 & 5.3 \\
\hline$l p_{10}$ & 3 & 3 & 3 & 0 & 0 & 0 & 1.2 & 3.6 \\
\hline$l p_{11}$ & 3 & 9 & 3 & 9 & 0 & 0 & 0.6 & 4.9 \\
\hline$l p_{12}$ & 9 & 9 & 3 & 9 & 9 & 3 & 0.8 & 11.2 \\
\hline$l p_{13}$ & 1 & 0 & 1 & 9 & 0 & 0 & 0.9 & 3.4 \\
\hline$l p_{14}$ & 3 & 0 & 3 & 1 & 9 & 1 & 0.8 & 4.3 \\
\hline$l p_{15}$ & 3 & 0 & 0 & 3 & 3 & 9 & 1.3 & 8.0 \\
\hline$l p_{16}$ & 9 & 3 & 1 & 3 & 3 & 3 & 0.9 & 6.8 \\
\hline$l p_{17}$ & 9 & 9 & 1 & 3 & 3 & 3 & 1.0 & 9.5 \\
\hline$l p_{18}$ & 9 & 9 & 1 & 9 & 1 & 3 & 0.8 & 8.8 \\
\hline$l p_{19}$ & 1 & 3 & 0 & 1 & 1 & 3 & 1.0 & 3.1 \\
\hline$l p_{20}$ & 9 & 3 & 0 & 3 & 3 & 1 & 0.9 & 5.9 \\
\hline$l p_{21}$ & 9 & 9 & 3 & 3 & 1 & 9 & 1.0 & 11.6 \\
\hline$l p_{22}$ & 0 & 1 & 0 & 3 & 0 & 0 & 0.9 & 1.2 \\
\hline
\end{tabular}

Although practice $l p_{21}$ (Workforce empowerment) has not been listed as important or critical, its value for implementation priority $\left(z_{21}=11.6\right)$ is the second largest among LP. This result can be particularly attributed to the fact that this practice has a high impact in the construction of a behavior consistent with hospital values. 
The nurses and technicians are the professionals who hold the greatest amount of contact with the patient, which implies that their behavior and performance are closely linked to the patients' perception of value. Thus, an autonomous team allows greater efficiency in the execution of daily activities, without affecting the service level offered to patients. In addition, leaders understand that the investment needed to achieve the full adoption of this practice is relatively low and its application is widespread. Similarly, $I p_{6}(5 \mathrm{~S})$ does not have high values of importance or criticality, but was considered a priority mainly due to the low effort related to its adoption and potential for adapting to any area, such as equipment rooms and warehouse, which present a great diversity of critical items for the operation of the ER. Finally, $l p_{12}$ (Error-proof systems) appears as a priority due to its low technical risk, low investment need, high relation with the accomplishment of the strategic goals and the construction of a behavior consistent with the organization. This practice has easy adaptation and, through simple mechanisms, enables the reduction of the defect causes improving the quality of the services provided. Considering the great complexity of the medical activity within the ED and the large number of interventions that a patient is subject to, there is a great risk of incidence of errors in these procedures, which can generate irreversible impacts on the patient.

\section{Conclusion}

The purpose of this study was to propose a methodology for assessing LP in healthcare organizations that are undergoing a lean implementation. Implications of this study are of considerable importance and relevance for both researchers and lean practitioners. The following sections describe in depth the contributions, and highlight the main study's limitations and future research opportunities.

\subsection{Contributions to theory}

In theoretical terms, the proposed methodology combines complementary concepts and methods aiming to evaluate healthcare organizations and help managers identify the relationships intensities between their problems and practices. Despite the number of studies about LH available in the literature (e.g. Miller, 2005; Kim et al., 2006; Ballé \& Régnier, 2007; Fillingham, 2007; Mazzocato et al., 2010), there is still a lack of evidence regarding research containing methods to evaluate LP implementation in healthcare. Due to such scarcity, it is very difficult to assess whether an organization has actually implemented lean principles and practices and the level of its adoption in relation to other organizations, as pointed by Wan \& Chen (2008). In this sense, the integration of the existing problems' occurrence, the adoption level of LP and the decision support criteria in the healthcare organization provides a theoretical framework that addresses LP according to fundamental aspects of the organization, such as: people, partnerships, results, processes and leadership. Further, this method allows a longitudinal assessment of the evolution throughout $\mathrm{LH}$ implementation, which is indicated as key by Bhasin (2011).

This framework consists of a normative theory for $\mathrm{LH}$ implementation, since it refers to the development of guidance on how actions will lead to desired results (Carlile \& Christensen, 2004). The proposed guidance refers to the LP to be prioritized and implemented, taking into account peculiarities of the assessed system. While this prescription may appear obvious in hindsight, it seems to be typically neglected by both academics and practitioners. Hence, this framework allows $\mathrm{LH}$ implementation to be addressed in a broader way, corroborating to a systemic view of lean implementation and facilitating its long-term sustainability; which is a distinctive feature in comparison with other studies in the area.

\subsection{Managerial implications}

Some managerial contributions must be highlighted. Our results provide hospital managers and leaders a clear focus on the improvement efforts that can mitigate the frequency of problems and strengthen the desired LH culture. Further, since most LP were originally conceived in traditional manufacturing environments, their understanding and, hence, adaptation to healthcare context features an additional challenge. The justification for that is twofold. First, personnel training in healthcare sectors does not emphasize the development of managerial skills. These professionals usually come with technical backgrounds that focus on aspects related to healthcare task performance rather than on process analysis from a horizontal perspective. Second, despite the increasing pressure for better performance of public healthcare services, the difference in the mindset of managers in private and public sectors is still large. While in the private sector managers must improve and optimize resources to financially sustain their businesses, public sector operations are usually supported by governmental institutions, 
whose primary objectives do not necessarily involve attaining financial profit or business performance. In this sense, an assertive selection of improvement initiatives allows to maximize results while minimizes the required efforts and investments related to $\mathrm{LH}$ implementation.

Also, the research method and the proposed improvement opportunities may help practitioners to solve real life problems related to the implementation of lean in public healthcare organizations. For the healthcare organization under study, our research worked as a basis for continuous improvement of the lean implementation process. For other organizations or departments, especially those sharing a similar context, the approach provides comparative parameters either in terms of problems occurrence or LP adoption level. However, it is worth to notice that, depending on the management decision criteria, the LP priorities indicated in our study are not valid. Therefore, further adaptations might be needed in order to replicate the proposed method.

Finally, by considering the proposed method to plan their LH implementation, managers can customize their design and prioritize improvement efforts that would actually mitigate relevant problems to the department/organization. Such approach allows a more assertive implementation which provides an increase in change acceptance and confidence level. This fact also enhances personnel engagement and buy-in, since a $\mathrm{LH}$ implementation that effectively addresses problems observed by most of the employees is more likely to be supported and, hence, sustained.

\subsection{Limitations and future research}

Some drawbacks should be highlighted. First, using a single case study (ED of a public hospital) for testing theory fundamentals could pose as a limitation to the validity and generalization of our results. To cope with that limitation, we follow a robust and structured research method that could be replicable to other case studies. That level of detail allows the proposed method to be carried on within organizations presenting similar background to the one addressed in this study, such as other healthcare organizations (public or private). As we stated before, the research method is also a contribution of our study, as it highlights priorities of improvements from a holistic point of view. We acknowledge that improvement opportunities should vary between different organizations, as lean is heavily dependent on context, but some opportunities may be very similar in other organizations. Nevertheless, since the encompassed improvement practices solely derive from $\mathrm{LH}$ approach, other improvement methods and management techniques available in the Industrial Engineering/Business Management spectrum are not considered. Such methods and techniques may either complement or even address issues that the single application of $\mathrm{LH}$ practices cannot. Thus, the alignment of the proposed method with other relevant methods and techniques characterizes another future research opportunity.

Further, implementing $\mathrm{LH}$ reinforces the need for re-orientation of public services regarding scope and strategic positioning. The evolutionary process of transferring the lean team-based approach to public healthcare organizations may enable that re-orientation. However, existing practices discourage the establishment of a transparency culture, where abnormalities and problems could be identified by anyone. Since the methodology is dependent on the opinion of employees involved in data collection, that fact may limit their perception with respect to problems occurrence and LP adoption level. Additionally, the observed results may be impacted due to the variation of understanding of $\mathrm{LP}$ and sensitivity to existing problems among employees. Thus, future research should address the underlying variances to respondents' profiles through the inclusion of more sophisticated statistical methods, allowing for more robust and reliable investigation and guidance for LH implementation. Further, these studies need to better understand the barriers and policies within different public sectors, enabling a proper adaptation of lean principles and maximize their acceptance by public healthcare organizations. It is worth noticing that an increase on the sample size would also benefit the research outcomes, allowing the establishment of more refined statistical analysis on the data (e.g. multivariate data analysis) and empirical validation of our findings.

\section{References}

Achanga, P., Shehab, E., Roy, R., \& Nelder, G. (2006). Critical success factors for lean implementation within SMEs. Journal of Manufacturing Technology Management, 17(4), 460-471. http://dx.doi.org/10.1108/17410380610662889.

Al-Balushi, S., Sohal, A., Singh, P., Al Hajri, A., Al Farsi, Y., \& Al Abri, R. (2014). Readiness factors for lean implementation in healthcare settings: a literature review. Journal of Health Organization and Management, 28(2), 135-153. http://dx.doi.org/10.1108/JHOM04-2013-0083. PMid:25065107.

Anvari, A., Zulkifli, N., \& Arghish, O. (2014a). Application of a modified VIKOR method for decision-making problems in lean tool selection. International Journal of Advanced Manufacturing Technology, 71(5-8), 829-841. http://dx.doi.org/10.1007/s00170-013-5520-x. 
Anvari, A., Zulkifli, N., Sorooshian, S., \& Boyerhassani, O. (2014b). An integrated design methodology based on the use of group AHP-DEA approach for measuring lean tools efficiency with undesirable output. International Journal of Advanced Manufacturing Technology, 70(9-12), 2169-2186. http://dx.doi.org/10.1007/s00170-013-5369-z.

Augusto, B., \& Tortorella, G. (2017). Literature review on Lean Healthcare implementation: assessment methods and practices. International Journal of Services and Operations Management

Ballé, M., \& Régnier, A. (2007). Lean as a learning system in a hospital ward. Leadership in Health Services, 20(1), 33-41. http://dx.doi. org/10.1108/17511870710721471. PMid:20690474.

Bastian, N., Munoz, D., \& Ventura, M. (2016). A mixed-methods research framework for healthcare process improvement. Journal of Pediatric Nursing, 31(1), e39-e51. http://dx.doi.org/10.1016/j.pedn.2015.09.003. PMid:26453414.

Ben-Tovim, D. 1., Bassham, J. E., Bennett, D. M., Dougherty, M. L., Martin, M. A., O’Neill, S. J., Sincock, J. L., \& Szwarcbord, M. G. (2008). Redesigning care at the Flinders Medical Center: clinical process redesign using lean thinking. The Medical Journal of Australia, 188(6), 27-31.

Bessant, J., \& Francis, D. (1999). Developing strategic continuous improvement capability. International Journal of Operations \& Management, 19(11), 1106-1119. http://dx.doi.org/10.1108/01443579910291032.

Bhasin, S. (2011). Measuring the leanness of an organisation. International Journal of Lean Six Sigma, 2(1), 55-74. http://dx.doi. org/10.1108/20401461111119459.

Bhat, S., Gijo, E., \& Jnanesh, N. (2014). Application of Lean Six Sigma methodology in the registration process of a hospital. International Journal of Productivity and Performance Management, 63(5), 613-643. http://dx.doi.org/10.1108/lJPPM-11-2013-0191.

Braaten, J., \& Bellhouse, D. (2007). Improving patient care by making small sustainable changes: a cardiac telemetry unit's experience. Nursing Economics, 25(3), 162-166. PMid:17802999.

Bush, R. (2007). Reducing waste in US health care systems. Journal of the American Medical Association, 2978), 871-874. http://dx.doi. org/10.1001/jama.297.8.871. PMid:17327529.

Carlile, P., \& Christensen, C. (2004). The cycles of theory building in management research. Boston: Harvard Business School, Boston University. Working paper 05-057, version 5.0.

Carvalho, J., Ramos, M., \& Paixão, C. (2013). A lean case study in an oncological hospital: implementation of a telephone triage system in the emergency service. Risk Management and Healthcare Policy, 7, 1-10. http://dx.doi.org/10.2147/RMHP.S49535. PMid:24376365.

Casey, J., Brinton, T., \& Gonzalez, C. (2009). Utilization of lean management principles in the ambulatory clinic setting. Nature Clinical Practice: Urology, 6(3), 146-153. PMid:19265856.

Cookson, D., Read, C., Mukherjee, P., \& Cooke, M. (2011). Improving the quality of Emergency Department care by removing waste using Lean Value Stream mapping. The International Journal of Clinical Leadership, 17(1), 25-30.

Costa, L., \& Godinho Filho, M. (2016). Lean healthcare: review, classification and analysis of literature. Production Planning and Control, 27(10), 823-836. http://dx.doi.org/10.1080/09537287.2016.1143131.

D’Andreamatteo, A., lanni, L., Lega, F., \& Sargiacomo, M. (2015). Lean in healthcare: a comprehensive review. Health Policy, 119(9), 1197-1209. http://dx.doi.org/10.1016/j.healthpol.2015.02.002. PMid:25737260.

Dahlgaard, J. J., \& Mi Dahlgaard-Park, S. (2006). Lean production, six sigma quality, TQM and company culture. The TQM Magazine, 18(3), 263-281. http://dx.doi.org/10.1108/09544780610659998.

Dahlgaard, J., Pettersen, J., \& Dahlgaard-Park, S. (2011). Quality and lean health care: a system for assessing and improving the health of healthcare organisations. Total Quality Management \& Business Excellence, 22(6), 673-689. http://dx.doi.org/10.1080/14783 363.2011.580651.

Daultani, Y., Chaudhuri, A., \& Kumar, S. (2015). A decade of lean in healthcare: current state and future directions. Global Business Review, 16(6), 1082-1099. http://dx.doi.org/10.1177/0972150915604520.

Dickson, E., Singh, S., Cheung, D., Wyatt, C., \& Nugent, A. (2009). Application of lean manufacturing techniques in the emergency department. The Journal of Emergency Medicine, 372), 177-182. http://dx.doi.org/10.1016/j.jemermed.2007.11.108. PMid:18722732.

Drotz, E., \& Poksinska, B. (2014). Lean in healthcare from employees' perspectives. Journal of Health Organization and Management, 28(2), 177-195. http://dx.doi.org/10.1108/JHOM-03-2013-0066. PMid:25065109.

Esain, A., Williams, S., \& Massey, L. (2008). Combining planned and emergent change in a healthcare lean transformation. Public Money \& Management, 28(1), 21-26.

Fillingham, D. (2007). Can lean save lives? Leadership in Health Services, 20(4), 231-241. http://dx.doi.org/10.1108/17511870710829346. PMid:20698096.

Furman, C., \& Caplan, R. (2007). Applying the Toyota Production System: using a patient safety alert system to reduce error. Joint Commission Journal on Quality and Patient Safety, 33(7), 376-386. http://dx.doi.org/10.1016/S1553-7250(07)33043-2. PMid:17711139.

Gijo, E., \& Antony, J. (2014). Reducing patient waiting time in outpatient department using lean six sigma methodology. Quality and Reliability Engineering International, 30(8), 1481-1491. http://dx.doi.org/10.1002/qre.1552.

Giovinazzo, R. (2001). Modelo de aplicação de metodologia Delphi pela internet: vantagens e ressalvas. Administração On Line, 2(2), 1-11.

Graban, M. (2012). Lean hospitals: improving quality, patient safety, and employee satisfaction. New York: Productivity Press.

Grout, J., \& Toussaint, J. (2010). Mistake-proofing healthcare: why stopping processes may be a good start. Business Horizons, 53(2), 149-156. http://dx.doi.org/10.1016/j.bushor.2009.10.007.

Jeyaraman, K., \& Kee Teo, L. (2010). A conceptual framework for critical success factors of lean six sigma. International Journal of Lean Six Sigma, 1(3), 191-215. http://dx.doi.org/10.1108/20401461011075008.

Jones, D. (2006). Leaning healthcare. Management Services, 50(2), 16-17.

Kim, C., Hayman, J., Billi, J., Lash, K., \& Lawrence, T. (2007). The application of lean thinking to the care of patients with bone and brain metastasis with radiation therapy. Journal of Oncology Practice, 3(4), 189-193. http://dx.doi.org/10.1200/JOP.0742002. PMid:20859409. 
Kim, C., Spahlinger, D., Kin, J., \& Billi, J. (2006). Lean health care: What can hospitals learn from a world-class automaker? Journal of Hospital Medicine, 1(3), 191-199. http://dx.doi.org/10.1002/jhm.68. PMid:17219493.

Kimsey, D. B. (2010). Lean methodology in health care. AORN Journal, 92(1), 53-60. http://dx.doi.org/10.1016/j.aorn.2010.01.015. PMid:20619772.

Kollberg, B., Dahlgaard, J., \& Brehmer, P. (2006). Measuring lean initiatives in health care services: issues and findings. International Journal of Productivity and Performance Management, 56(1), 7-24. http://dx.doi.org/10.1108/17410400710717064.

Kothari, R. (2004). Research methodology: methods and techniques. New Delhi: New Age International.

Laganga, L. (2011). Lean service operations: reflections and new directions for capacity expansion in outpatient clinics. Journal of Operations Management, 29(5), 422-433. http://dx.doi.org/10.1016/j.jom.2010.12.005.

Laureani, A., Brady, M., \& Antony, J. (2013). Applications of lean six sigma in an lrish hospital. Leadership in Health Services, 26(4), 322-337. http://dx.doi.org/10.1108/LHS-01-2012-0002.

Leslie, M., Hagood, C., Royer, A., Reece Junior, C., \& Maloney, S. (2006). Using lean methods to improve OR turnover times. AORN Journal, 84(5), 849-855. http://dx.doi.org/10.1016/S0001-2092(06)63971-9. PMid:17144053.

Liker, J. (2004). The Toyota way: 14 principles of world's greatest manufacturer. Madison: McGraw-Hill.

Lummus, R., Vokurka, R., \& Rodeghiero, B. (2006). Improving quality through value stream mapping: a case study of a physician's clinic. Total Quality Management, 17(8), 1063-1075. http://dx.doi.org/10.1080/14783360600748091.

Mann, D. (2005). Creating a lean culture: tools to sustain lean conversions. New York: Productivity Press. http://dx.doi. org/10.4324/9781420080971.

Mannon, M. (2014). Lean healthcare and quality management: the experience of ThedaCare. The Quality Management Journal, 21(1), 7-10. http://dx.doi.org/10.1080/10686967.2014.11918371.

Marodin, G., \& Saurin, T. (2013). Implementing lean production systems: research areas and opportunities for future studies. International Journal of Production Research, 51(22), 6663-6680. http://dx.doi.org/10.1080/00207543.2013.826831.

Mazzocato, P., Savage, C., Brommels, M., Aronsson, H., \& Thor, J. (2010). Lean Thinking in healthcare: a realist review of the literature. Quality \& Safety in Health Care, 19(5), 376-382. PMid:20724397.

McConnell, K., Chang, A., Maddox, T., Wholey, D., \& Lindrooth, R. (2014). An exploration of management practices in hospitals. Health Care, 2(2), 121-129. PMid:26250380.

Miller, D. (2005). Going lean in health care. Cambridge: Institute for Healthcare Improvement.

Pavnaskar, S., Gershenson, J., \& Jambekar, A. (2003). Classification scheme for lean manufacturing tools. International Journal of Production Research, 41(13), 3075-3090. http://dx.doi.org/10.1080/0020754021000049817.

Persoon, T., Zaleski, S., \& Frerichs, J. (2006). Improving preanalytic processes using the principles of lean production (Toyota Production System). American Journal of Clinical Pathology, 125(1), 16-25. http://dx.doi.org/10.1309/865V7UMFPUKGCF8D. PMid:16482987.

Poksinska, B. (2010). The current state of Lean implementation in health care: literature review. Quality Management in Health Care, 19(4), 319-329. http://dx.doi.org/10.1097/QMH.0b013e3181fa07bb. PMid:20924253.

Proudlove, N., Moxham, C., \& Boaden, R. (2008). Lessons for lean in healthcare from using six sigma in the NHS. Public Money \& Management, 28(1), 27-34.

Raab, S., Grzybicki, D., Condel, J., Stewart, W., Turcsanyi, B., Mahood, L., \& Becich, M. (2008). Effect of lean method implementation in the histopathology section of an anatomical pathology laboratory. Journal of Clinical Pathology, 61(11), 1193-1199. http://dx.doi. org/10.1136/jcp.2007.051326. PMid:17675533.

Radnor, Z., Holweg, M., \& Waring, J. (2012). Lean in healthcare: the unfilled promise? Social Science \& Medicine, 74(3), 364-371. http://dx.doi.org/10.1016/j.socscimed.2011.02.011. PMid:21414703.

Rechel, B., Wright, S., Barlow, J., \& McKee, M. (2010). Hospital capacity planning: from measuring stocks to modelling flows. Bulletin of the World Health Organization, 88(8), 632-636. http://dx.doi.org/10.2471/BLT.09.073361. PMid:20680129.

Righi, A., \& Saurin, T. (2015). Complex socio-technical systems: characterization and management guidelines. Applied Ergonomics, 50, 19-30. http://dx.doi.org/10.1016/j.apergo.2015.02.003. PMid:25959314.

Ruiz, U., \& Simon, J. (2004). Quality management in health care: a 20-year journey. International Journal of Health Care Quality Assurance, 17(6), 323-333. http://dx.doi.org/10.1108/09526860410557570. PMid:15552387.

Saurin, T., Rooke, J., \& Koskela, L. (2013). A complex systems theory perspective of lean production. International Journal of Production Research, 51(19), 5824-5838. http://dx.doi.org/10.1080/00207543.2013.796420.

Shah, R., \& Ward, P. (2007). Defining and developing measures of lean production. Journal of Operations Management, $25(4), 785-805$. http://dx.doi.org/10.1016/j.jom.2007.01.019.

Shannon, R., Frndak, D., Grunden, N., Lloyd, J. C., Herbert, C., Patel, B., Cummins, D., Shannon, A. H., O’Neill, P. H., \& Spear, S. J. (2006). Using real-time problem solving to eliminate central line infections. Joint Commission Journal on Quality and Patient Safety, 32(9), 479-487. http://dx.doi.org/10.1016/S1553-7250(06)32063-6. PMid:17987871.

Shingo Prize. (2014). The Shingo Prize for operational excellence: application guidelines. Utah. Retrieved in 2016, May 29, from http:// www.shingoprize.org/

Silberstein, A. 2006. Um estudo de casos sobre a aplicação de princípios enxutos em serviços de saúde no Brasil (Dissertação de mestrado). Instituto de Pós-graduação e Pesquisa em Administração, Universidade Federal do Rio de Janeiro, Rio de Janeiro.

Society of Automotive Engineers - SAE. (1999). SAE J4000: identification and measurement of best practice in implementation of lean operation. Warrendale: SAE.

Souza, L. (2009). Trends and approaches in lean healthcare. Leadership in Health Services, 22(2), 121-139. http://dx.doi. org/10.1108/17511870910953788.

Souza, L., \& Pidd, M. (2011). Exploring the barriers to lean health care implementation. Public Money \& Management, 31(1), 59-66. http://dx.doi.org/10.1080/09540962.2011.545548. 
Spear, S. (2004). Learning to lead at Toyota. Harvard Business Review, 82(5), 78-86. PMid:15146738.

Spear, S. (2005). Fixing health care from the inside today. Harvard Business Review, 83(9), 78-91, 158. PMid:16171213.

Spear, S. (2009). The high-velocity edge: how market leaders leverage operational excellence to beat the competition. New York, McGraw-Hill.

Tortorella, G., \& Fogliatto, F. (2014). Method for assessing human resources management practices and organizational learning factors in a company under lean manufacturing implementation. International Journal of Production Research, 52(15), 4623-4645. http:// dx.doi.org/10.1080/00207543.2014.881577.

Tortorella, G., Fogliatto, F., Anzanello, M., Marodin, G., Garcia, M., \& Reis Esteves, R. (2017a). Making the value flow: application of value stream mapping in a Brazilian public healthcare organisation. Total Quality Management \& Business Excellence, 28(13-14), 1544-1558. http://dx.doi.org/10.1080/14783363.2016.1150778.

Tortorella, G., Marodin, G., Miorando, R., \& Seidel, A. (2015). The impact of contextual variables on learning organization in firms that are implementing lean: a study in Southern Brazil. International Journal of Advanced Manufacturing Technology, 78(9-12), 1879-1892. http://dx.doi.org/10.1007/s00170-015-6791-1.

Tortorella, G., Vergara, L., \& Ferreira, E. (2017b). Lean manufacturing implementation: an assessment method with regards to sociotechnical and ergonomics practices adoption. International Journal of Advanced Manufacturing Technology, 89(9-12), 3407-3418. http://dx.doi.org/10.1007/s00170-016-9227-7.

Tréville, S., \& Antonakis, J. (2006). Could lean production job design be intrinsically motivating? Contextual, configurational, and levelsof-analysis issues. Journal of Operations Management, 24(2), 99-123. http://dx.doi.org/10.1016/j.jom.2005.04.001.

Vinodh, S., \& Chintha, S. (2011). Leanness assessment using multi-grade fuzzy approach. International Journal of Production Research, 49(2), 431-445. http://dx.doi.org/10.1080/00207540903471494.

Vinodh, S., Shivraman, K., \& Viswesh, S. (2011). AHP-based lean concept selection in a manufacturing organization. Journal of Manufacturing Technology Management, 23(1), 124-136. http://dx.doi.org/10.1108/17410381211196320.

Waldhausen, J., Avansino, J., Libby, A., \& Sawin, R. (2010). Application of lean methods improves surgical clinic experience. Journal of Pediatric Surgery, 45(7), 1420-1425. http://dx.doi.org/10.1016/j.jpedsurg.2009.10.049. PMid:20638518.

Wan, H., \& Chen, F. (2008). A leanness measure of manufacturing systems for quantifying impacts of Lean initiatives. International Journal of Production Research, 46(23), 6567-6584. http://dx.doi.org/10.1080/00207540802230058.

Yew Wong, K. (2005). Critical success factors for implementing knowledge management in small and medium enterprises. Industrial Management \& Data Systems, 105(3), 261-279. http://dx.doi.org/10.1108/02635570510590101.

Young, T., \& McClean, S. (2008). A critical look at lean thinking in healthcare. Quality \& Safety in Health Care, 17(5), 382-386. http:// dx.doi.org/10.1136/qshc.2006.020131. PMid:18842980.

Young, T., \& McClean, S. (2009). Some challenges facing lean thinking in healthcare. International Journal for Quality in Health Care, 21(5), 309-310. http://dx.doi.org/10.1093/intqhc/mzp038. PMid:19749078.

Zarbo, R., \& D'Angelo, R. (2007). The Henry ford production system: effective reduction of process defects and waste in surgical pathology. American Journal of Clinical Pathology, 128(6), 1015-1022. http://dx.doi.org/10.1309/RGF6JD1NAP2DU88Q. PMid:18024328.

Zarbo, R., Tuthill, J., D’Angelo, R., Varney, R., Mahar, B., Neuman, C., \& Ormsby, A. (2009). The Henry Ford Production System reduction of surgical pathology in-process misidentification defects by bar code: specified work process standardization. American Journal of Clinical Pathology, 131(4), 468-477. http://dx.doi.org/10.1309/AJCPPTJ3XJY6ZXDB. PMid:19289582. 
Appendix A. Questionnaire for identification of problems' occurrence frequency in ED.

\begin{tabular}{|c|c|c|c|c|c|}
\hline & CSF and problems & Mean & $f_{\mathrm{k}}$ & $f p_{\mathrm{k}}$ & $p_{\mathrm{j}}$ \\
\hline \multirow{10}{*}{ 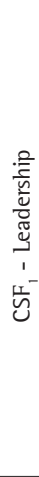 } & $\begin{array}{l}f_{1} \text { - Managers are role models and good teachers of the hospital's philosophy and way of } \\
\text { practicing lean principles. }\end{array}$ & 2.81 & 0.56 & 0.44 & \multirow{10}{*}{0.49} \\
\hline & $f_{2}$ - Management always expresses their recognition when employees have made a good effort. & 2.19 & 0.44 & 0.56 & \\
\hline & $f_{3}$ - Management makes great efforts to improve communication in the company. & 2.61 & 0.52 & 0.48 & \\
\hline & $f_{4}$ - Management regularly evaluates employees' involvement in waste reduction projects. & 2.03 & 0.41 & 0.59 & \\
\hline & $f_{5}$ - Management grants sufficient resources for employee's education and training. & 2.81 & 0.56 & 0.44 & \\
\hline & $f_{6}$ - When determining objectives and strategies management involves the employees. & 2.61 & 0.52 & 0.48 & \\
\hline & $f_{7}$ - The hospital's innovation culture is based on a continuous focus on patients' needs. & 2.77 & 0.55 & 0.45 & \\
\hline & $\begin{array}{l}f_{8} \text { - The organisation is characterised by an innovative culture where employees have time to think } \\
\text { freely and follow up on own ideas, learn of experiences, etc. }\end{array}$ & 2.19 & 0.44 & 0.56 & \\
\hline & $f_{9}$ - Visions, goals and strategies for innovations are developed elecidas. & 2.71 & 0.54 & 0.46 & \\
\hline & $f_{10}$ - Visions, goals and strategies for innovations are communicated clearly to everybody. & 2.55 & 0.51 & 0.49 & \\
\hline \multirow{10}{*}{5} & $\begin{array}{l}f_{11} \text { - The organisation makes an ongoing effort to train individuals how to work together as teams } \\
\text { toward common goals. }\end{array}$ & 2.42 & 0.48 & 0.52 & \multirow{10}{*}{0.54} \\
\hline & $\begin{array}{l}f_{12} \text { - The organisation continuously evaluates the efforts made by employees in relation to the } \\
\text { jointly established objectives. }\end{array}$ & 2.45 & 0.49 & 0.51 & \\
\hline & $\begin{array}{l}f_{13} \text { - The organisation establishes, in co-operation with the employees, objectives for the following } \\
\text { period.odo. }\end{array}$ & 2.29 & 0.46 & 0.54 & \\
\hline & $f_{14}$ - The organisation continuously evaluates the skills and attitudes of the employees. & 2.84 & 0.57 & 0.43 & \\
\hline & $f_{15}$ - The organisation composes in co-operation with each employee an education plan. & 2.45 & 0.49 & 0.51 & \\
\hline & $f_{16}$ - The organisation listen to the employees and follow-up on their comments. & 2.23 & 0.45 & 0.55 & \\
\hline & $\begin{array}{l}f_{17} \text { - Management continuously encourages employees to make proposals for the improvement of } \\
\text { their daily work/routines. }\end{array}$ & 2.13 & 0.43 & 0.57 & \\
\hline & $\begin{array}{l}f_{18} \text { - Feedback is given to the individual as well as to the team concerning improvement } \\
\text { suggestions for innovation. }\end{array}$ & 2.35 & 0.47 & 0.53 & \\
\hline & $\begin{array}{l}f_{19} \text { - Employees who contribute actively to process or result objectives within the innovation area } \\
\text { are in some way promoted, empowered, recognised or rewarded. }\end{array}$ & 1.81 & 0.36 & 0.64 & \\
\hline & $\begin{array}{l}f_{20} \text { - Employees are empowered to make decisions about their innovation projects and participate } \\
\text { in the planning and decision making for innovation. }\end{array}$ & 2.13 & 0.43 & 0.57 & \\
\hline \multirow{10}{*}{ 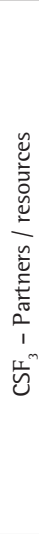 } & $\begin{array}{l}f_{21} \text { - Cross-functional teams are used to improve quality and productivity and enhance flow by } \\
\text { solving difficult technical and other problems. }\end{array}$ & 3.00 & 0.60 & 0.40 & \multirow{10}{*}{0.49} \\
\hline & $f_{22}$ - The organization identifies strategic partners for improvement of innovation processes. & 2.61 & 052 & 0.48 & \\
\hline & $\begin{array}{l}f_{23} \text { - We show respect for our external partners and suppliers and treat them as an extension of } \\
\text { our organization. }\end{array}$ & 2.71 & 0.54 & 0.46 & \\
\hline & $f_{24}$ - We have agreements and yearly goals for external customer-supplier relationships. & 2.48 & 0.50 & 0.50 & \\
\hline & $f_{25}$ - The resources necessary for the company's innovation programs are clearly mapped out. & 2.39 & 0.48 & 0.52 & \\
\hline & $f_{26}$ - The hospital has objectives and standards for how it-resources are to be managed. & 2.68 & 0.54 & 0.46 & \\
\hline & $\begin{array}{l}f_{27} \text { - The department has written objectives and standards for how tangible resources are to be } \\
\text { managed. }\end{array}$ & 2.52 & 0.50 & 0.50 & \\
\hline & $\begin{array}{l}f_{28}-\text { Information on errors and problems are systematically used for improvements of the } \\
\text { exploitation of resources. }\end{array}$ & 2.42 & 0.48 & 0.52 & \\
\hline & $f_{29}$ - The department systematically plans for maintenance of machinery and other equipment. & 2.48 & 0.50 & 0.50 & \\
\hline & $f_{30}$ - The department regularly measures waste of materials and other resources. & 2.03 & 0.41 & 0.59 & \\
\hline \multirow{10}{*}{$\begin{array}{l}\tilde{U} \\
\tilde{U} \\
0 \\
0 \\
1 \\
\tilde{D}^{+}\end{array}$} & $f_{31}$ - The organisation is continuously striving to reduce waiting time for patients or projects. & 2.35 & 0.47 & 0.53 & \multirow{10}{*}{0.51} \\
\hline & $f_{32}$ - Organisational learning is ensured through standardising today's best practices. & 2.61 & 0.52 & 0.48 & \\
\hline & $f_{33}$ - People contribute with creative and individual suggestions to improve standards. & 2.48 & 0.50 & 0.50 & \\
\hline & $f_{34}$ - Visual systems to support flow and pull are in place at the place where the work is done. & 2.61 & 0.52 & 0.48 & \\
\hline & $\begin{array}{l}f_{35} \text { - Thoroughly considered technologies are quickly implemented if they can improve flow in } \\
\text { processes. }\end{array}$ & 2.29 & 0.46 & 0.54 & \\
\hline & $f_{36}$ - Problems are solved by going to the source and personally observing and verifying data. & 2.65 & 0.53 & 0.47 & \\
\hline & $f_{37}$ - Continuous improvement tools are used to determine the root cause of inefficiencies. & 2.29 & 0.46 & 0.54 & \\
\hline & $f_{38}$ - Employees are trained to use a formal/standardised improvement process. & 2.52 & 0.50 & 0.50 & \\
\hline & 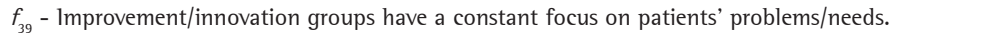 & 2.45 & 0.49 & 0.51 & \\
\hline & $f_{40}$ - Process measurements have been established for all important processes. & 2.23 & 0.45 & 0.55 & \\
\hline
\end{tabular}

Source: Adapted from Dahlgaard et al. (2011). 
Appendix A. Continued...

\begin{tabular}{|c|c|c|c|c|c|}
\hline & CSF and problems & Mean & $f_{\mathrm{k}}$ & $f p_{k}$ & $p_{\mathrm{j}}$ \\
\hline \multirow{10}{*}{ 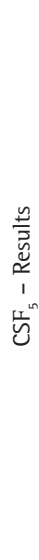 } & $f_{41}$ - Patients' satisfaction has been improved during the last 3 years. & 2.81 & 0.56 & 0.44 & \multirow{10}{*}{0.50} \\
\hline & $\begin{array}{l}f_{42} \text { - Clinical outcomes have been improved during the last } 3 \text { years (Wellness, malpractice, } \\
\text { infections, adverse events, morbidity, mortality rates, etc.). }\end{array}$ & 2.74 & 0.55 & 0.45 & \\
\hline & $\begin{array}{l}f_{43} \text { - Efficiency indicators have been improved during the last } 3 \text { years (Bed Occupancy Rate, bed } \\
\text { turnover rate, etc.). }\end{array}$ & 2.45 & 0.49 & 0.51 & \\
\hline & $\begin{array}{l}f_{44} \text { - Effectiveness indicators have been improved during the last } 3 \text { years (mortality and morbidity } \\
\text { rates, etc.). }\end{array}$ & 2.81 & 0.56 & 0.44 & \\
\hline & $\begin{array}{l}f_{45} \text { - The organisation has a strong culture in which the hospital's values and beliefs are widely } \\
\text { shared and lived out. }\end{array}$ & 2.61 & 0.52 & 0.48 & \\
\hline & $f_{46}$ - Trust and respect between people have increased during the last 3 years. & 2.29 & 0.46 & 0.54 & \\
\hline & $f_{47}$ - Employees are committed to the goals of their improvement/innovation projects. & 2.58 & 0.52 & 0.48 & \\
\hline & $f_{48}$ - The employees' motivation and commitment have increased during the last 3 years. & 2.45 & 0.49 & 0.51 & \\
\hline & $\begin{array}{l}f_{49}-\text { Innovation/improvement programs' impact on overall performance has increased during the } \\
\text { last } 3 \text { years. }\end{array}$ & 2.13 & 0.43 & 0.57 & \\
\hline & $f_{50}$ - The hospital's overall image has improved during the last 3 years. & 2.19 & 0.44 & 0.56 & \\
\hline
\end{tabular}

Source: Adapted from Dahlgaard et al. (2011). 
Appendix B. Questionnaire for lean healthcare practices and the results for implementation level in ED.

\begin{tabular}{|c|c|c|c|}
\hline Lean healthcare practices & Mean & $n_{\mathrm{i}}$ & $g_{\mathrm{i}}$ \\
\hline$I p_{1}-$ Value stream mapping & 2.58 & 0.52 & 0.48 \\
\hline$I p_{2}$ - Visual management & 2.42 & 0.48 & 0.52 \\
\hline$I p_{3}-$ Operation standardization & 3.19 & 0.64 & 0.36 \\
\hline$I p_{4}-$ Continuous flow & 3.00 & 0.60 & 0.40 \\
\hline$I p_{5}-$ Pull system & 2.32 & 0.46 & 0.54 \\
\hline$I p_{6}-5 \mathrm{~S}$ & 2.45 & 0.49 & 0.51 \\
\hline$I p_{7}$ - Kaizen & 2.16 & 0.43 & 0.57 \\
\hline$I p_{8}$ - Problem solving methodology & 2.35 & 0.47 & 0.53 \\
\hline$I p_{9}$ - Production leveling & 2.84 & 0.57 & 0.43 \\
\hline$I p_{10}-$ Gemba walk & 2.29 & 0.46 & 0.54 \\
\hline$I p_{11}-$ Crossfunctional team & 3.77 & 0.75 & 0.25 \\
\hline$I p_{12}-$ Error-proof systems & 3.03 & 0.61 & 0.39 \\
\hline$I p_{13}-$ Operations balance & 2.77 & 0.55 & 0.45 \\
\hline$I p_{14}-$ Workplace design & 2.77 & 0.55 & 0.45 \\
\hline$I p_{15}-$ Kanban & 1.58 & 0.32 & 0.68 \\
\hline$I p_{16}-$ Setup reduction & 2.58 & 0.52 & 0.48 \\
\hline$I p_{17}-$ Andon & 2.71 & 0.54 & 0.46 \\
\hline$I p_{18}-$ Training/education & 3.23 & 0.65 & 0.35 \\
\hline$I p_{19}-$ Total productive maintenance & 2.35 & 0.47 & 0.53 \\
\hline$I p_{20}-$ Autonomation (Jidoka) & 2.74 & 0.55 & 0.45 \\
\hline$I p_{21}$ - Workforce empowerment & 2.81 & 0.56 & 0.44 \\
\hline$I p_{22}$ - Small batch sizes & 2.55 & 0.51 & 0.49 \\
\hline
\end{tabular}

